\title{
El Monólogo como método de análisis de una obra de teatro
}

\author{
The Monologue as a method for analyzing a play
}

\author{
Vicente Pereda \\ pereda.vicente@gmail.com \\ Código ORCID: 0000-0002-9151-9478 \\ Universidad Pedagógica Experimental Libertador, Caracas, Venezuela
}

| Artículo recibido en marzo 2021

| Arbitrado en abril 2021

| Aceptado en abril 2021

| Publicado en mayo 2021

\section{Resumen}

El presente artículo tiene como objetivo estudiar el monólogo como estrategia de enseñanza para el análisis de un texto dramático en obras teatrales, en específico el texto teatral Fotomatón (1995) del dramaturgo venezolano Gustavo Ott. Esta investigación de acuerdo a su naturaleza se encuentra enmarcada en el paradigma cualitativo y por la consideración de sus objetivos es descriptiva y documental. El método propuesto para la interpretación de las obras es el Interaccionismo Simbólico y la técnica para el análisis es la aplicación del instrumento semiótico Sistema Sígnico de Claves. Los fundamentos del proceso hermenéutico se basan en la interpretación de símbolos y el significado del lenguaje hablado y escrito, dando como resultado el monólogo. Luego la Información es sometida a un proceso de triangulación desde la relación textoinvestigador-contexto. Todos los textos literarios están interrelacionados con otros textos debido a una red semiótica llamada intertextualidad.

\footnotetext{
Abstract

The purpose of this article is to study the monologue as a teaching strategy for the analysis of a dramatic text in plays, specifically the theatrical text Fotomatón (1995) by the Venezuelan playwright Gustavo Ott. This research, according to its nature, is framed in the qualitative paradigm and by the consideration of its objectives it is descriptive and documentary. The method proposed for the interpretation of the works is Symbolic Interactionism and the technique for the analysis is the application of the semiotic instrument Symbolic System of Keys. The fundamentals of the hermeneutic process are based on the interpretation of symbols and the meaning of spoken and written language, resulting in the monologue. The information is then subjected to a triangulation process from the text-researcher-context relationship. All literary texts are interrelated with other texts due to a semiotic network called intertextuality.
}

\section{Palabras clave:}

Teatro venezolano; monólogo; Gustavo Ott; análisis; interaccionismo simbólico
Keywords:

Venezuelan theater; monologue; Gustavo Ott; analysis; symbolic interactionism 


\section{INTRODUCCIÓN}

Estudiar un texto dramático es una de las actividades más frecuentes en el hecho teatral, bien sea para llevar a escena un determinado autor, interpretar una época específica desde un punto de vista dramatúrgico, comprender géneros teatrales, estilo o develar elementos estéticos presentes en una obra teatral. Este estudio permitió la interpretación de un texto dramático del dramaturgo venezolano Gustavo Ott a través del monólogo como método de interpretación apoyado en el Interaccionismo Simbólico. En este sentido la técnica de análisis es el instrumento semiótico del Sistema Sígnico de claves propuesto por Gámez (2000) posteriormente la obra se identificó con el título, año de creación, año de estreno, el género teatral al que pertenece y el personaje presente en texto teatral seleccionado el cual fue Fotomatón (1995) Seguidamente se realizó el argumento, mencionando a grandes rasgos las acciones del personaje. Posteriormente se presentó un monólogo creado por el investigador, tomando en consideración la intertextualidad propuesta por Zavala (1999) y la obra de Ott.

Es importante señalar la importancia de la enseñanza de analizar y comprender una obra de teatro en las artes escénicas, debido a la existencia de códigos y símbolos los cuales se encuentran inmersos en un texto teatral, siendo útiles a la hora de interpretar personajes, estudiar contextos históricos, elementos estéticos, entre otras cualidades presentes en la dramaturgia, por ende, educar en esta senda radica en brindar herramientas efectivas y novedosas al educando, permitiéndole conocer y emplear a conciencia las partes de un texto dramático, tanto en forma externa como interna y así logre comprender la intención del autor, de igual manera, al aplicar la hermenéutica el estudiante inicia el proceso de interpretación considerando la triangulación del texto- contexto- investigador.

Ahora bien, se entiende como monólogo a la obra dramática donde el protagonista es un solo personaje y a su vez puede interpretar otros dentro de la misma obra, el proceso de creación inicia cuando el investigador se enfrenta a la obra dramática, iniciando el círculo hermenéutico comprendiendo así interpretar los códigos y símbolos presentes, posteriormente, el investigador inicia el análisis valiéndose de la intertextualidad.

En consecuencia el monólogo derivado fue el producto de la lectura-expectación del investigador ante el texto dramático, siendo identificándolo con un título, este se encuentra relacionado estrechamente con la obra a estudiar, bajo la interpretación crítica. De igual forma se identificaron las respectivas claves propuestas en la investigación, armonizando las categorías en un análisis final.

En la elaboración de este monólogo se tomó en consideración el paradigma cualitativo, según Hernández, Collado y Lucio (2003) consideran es utilizado para la "recolección de datos sin medición numérica para descubrir o afinar preguntas de investigación y puede o no probar hipótesis en su proceso de interpretación" (p. 11) Entonces, se pudo triangular la percepción del investigador, el texto de Ott y los elementos estéticos de lo macabro en situaciones sociales en Venezuela de 1995 a 1999 cuyo período está enmarcado en el contexto histórico de la obra.

\section{MÉTODO}

En relación a la metodología aplicada, Sandín (2003) indica que al utilizar un diseño metodológico cualitativo se desarrollan investigaciones en el área interpretativa, porque atañe a cuestiones humanas y se centran en aspectos individuales y cualitativos de las acciones de las personas, en este trabajo se tomó en cuenta el enfoque interpretativo, debido a que toca aspectos de la vida social desde una perspectiva artística cultural.

Profundizando en la concepción de la metodología Márquez (2008) citando a Sandín 
(2003) acota que la investigación cualitativa permite al investigador posicionarse del objeto de estudio durante el proceso, debido a la flexibilidad del paradigma, por lo tanto se debe tomar decisiones importantes en todo el proceso de indagación, sistematización e interpretación de la información, pues la construcción del conocimiento es permanente al igual que las acciones humanas, las cuales son protagonistas del estudio que se planteó, por lo tanto no siguen un patrón determinado como se hace en las investigaciones cuantitativas.

En este orden de ideas Márquez (2008) indica lo siguiente "La investigación cualitativa es un proceso permanente de producción de conocimiento, dondelos resultados son momentos parciales que se integran constantemente con nuevas interrogantes y abren nuevos caminos a la producción de conocimiento" (p. 48) En consecuencia, al analizar lo macabro se puede brindar al estudiante herramientas útiles para realizar un análisis dramático, ya que en esta investigación sepudo identificaralgunascategorías estéticas en el texto Fotomatón (1995) de Gustavo Ott a través de las situaciones sociales, también el educando puede obtener la información necesaria que permita interpretar un texto dramático y así aportar nuevos conocimientos en el ámbito de las artes escénicas.

En cuanto al paradigma de la investigación se selecciona el paradigma postpositivista, al respecto Arias (2008) refiere que este modelo se centra en las acciones humanas para su comprensión de los significados de acciones en determinados contextos, los cuales son elementos esenciales de los significados sociales (p. 17) Es decir, los hechos sociales son estudiados por el paradigma cualitativo y por ende las ciencias sociales, los cuales son susceptibles a diversas interpretaciones, en consecuencia la educación y el teatro se complementan para analizarlos y comprenderlos desde un contexto teatral, brindando así una nueva óptica de interpretación de la realidad social- teatral.
Asimismo Arias (2008) citando a Sandín (2003) refiere una serie de supuestos básicos que sustentan este modelo, describiendo que las acciones sociales se abordan desde una postura interpretativa y dinámica, puesto que los hechos sociales se encuentran interrelacionado por medio de símbolos y signos. De igual manera enuncia que "la supuesta objetividad se consigue conociendo el significado subjetivo que tiene la acción para su protagonista o ejecutor" (p. 18) es decir, el objetivo se alcanza comprendiendo el contexto que rodea las acciones individuo.

En relación al tipo de investigación es de carácter descriptivo y documental, por su parte Arias (2012) acota que la investigación descriptiva consiste en caracterizar determinado hecho "Con el fin de establecer su estructura o comportamiento. Los resultados de este tipo de investigación se ubican en un nivel intermedio en cuanto a la profundidad de los conocimientos se refiere" (p.24) es decir, se trata de señalar las características de determinado asunto. Por su parte Tamayo (2003) señala que la investigación descriptiva se basa en: "la descripción, registro, análisis e interpretación de la naturaleza actual, y la composición o procesos de los fenómenos. El enfoque se hace sobre conclusiones dominantes o sobre cómo una persona, grupo o cosa se conduce o funciona en el presente" (p. 46) en este sentido, el tema de estudio se delimita y señalan detalles o cualidades propios del hecho estudiado, seguidamente se registran las cualidades encontradas para luego realizar interpretación.

De este modo Hernández, Fernández-Collao y Baptista (2006) en su libro de Metodología de la investigación definen que en los estudios descriptivos el investigador explica o define determinado hecho o acción, sus cualidades características y/o dimensiones. 
Por consiguiente, el presente estudio tuvo como finalidad el análisis e interpretación de documentos relativos a la dramaturgia de Gustavo Ott y en especial a la obra Fotomatón (1995) y se tomó en cuenta investigaciones de otros autores. En torno a este punto Arias (2012) señala que este tipo de investigación se basa en buscar determinada información, organizarla para someterla a un proceso de análisis, de esta forma se realiza un nuevo aporte para el tema de estudio.

En cuanto a las técnicas de recolección corresponden a las diversas formas de obtener información esencial de cualquier estudio, al procesarse se convierte en hallazgos valiosos. En este sentido se encuentran los diversos documentos y por otro los propios individuos o sujetos de la investigación.

En el presente trabajo se tomó como técnica de recolección de la información el Análisis de Documentos, al respecto Vásquez, Rejane, Mogollón, Fernández, Sanmamed Delgado y Vargas (2006) señalan: "Los datos contenidos en un documento pueden usarse de la misma manera que los derivados de la entrevista y las observaciones y su utilización en combinación con otros documentos y técnicas de investigación enriquece los hallazgos de estudios" (p 74) la técnica seleccionada permitirá la verificación del o conceptos presentes en un contenido determinado, en este caso en el texto dramático Fotomatón (1995) Gustavo Ott.

En tal sentido al aplicar la técnica de análisis de documentos se pudo verificar $u$ obtener información novedosa en el campo del teatro, específicamente en la obra dramática escogida. Es importante agregar que se utilizó el Sistema Sígnico de Claves propuesta por Gámez (2000) en su trabajo titulado La Cárcel como Espacialidad Dramática en el discurso político del teatro latinoamericano contemporáneo.

De igual forma el presente Sistema se apoya en las denominadas "Imágenes Radicales" propuesta por Blumer (1982) cuyo autor es unos de los máximos exponente del Interaccionismo Simbólico, indicando que dichas imágenes "representan el modo en que el interaccionismo contempla el comportamiento y la sociedad humana. Constituye el armazón del estudio y el análisis" (p. 5)

Ahora se destacaron las tres premisas básicas del Interaccionismo Simbólico propuestas por Blumer (1982) por su aporte al desarrollo de éste trabajo. Tomando en cuenta dichas premisas se consideró la selección del textos dramático para su interpretación. La primera premisa se basa en cómo el ser humano actúa en función a las "cosas" que conoce y tiene significado para sí, en este sentido García (1999) citando a Blumer (1982) acota:

El significado que una cosa encierra para una persona, es el resultado de las distintas formas en que otras personas actúan hacia ellas en relación con esa cosa. Los actos de los demás, producen el efecto de definirle la cosa a esa persona, el significado es un producto social, una creación que emana de y las actividades definitorias de los individuos a medida que estos actúan. (p. 20)

Tomando en cuenta la cita anterior se comprende por "cosa" a personas, objetos, instituciones, actividades, valores, antivalores, entre otros, conocidos e identificados por el sujeto y su entorno. En la segunda premisa se encuentra el significado de las cosas que tiene para el individuo al momento de relacionarse con el otro, en cuanto a la tercera premisa Blumer (1982) considera que "Los significados se manipulan y modifican mediante un proceso interpretativo desarrollado por la persona al enfrentarse con las cosas que va hallando a su paso" es decir, el sujeto realiza un proceso de auto interpretación, selecionándo y organizando los símbolos y su significado, en el cual puede 
reproducir y transformar "la cosa" en función a sus objetivos.

Sobre la base de las consideraciones anteriores, es pertinente acotar para el análisis e interpretación de la obra seleccionada para este estudio, el autor se realizó un monólogo desde una interpretación crítica, resaltando la interacción simbólica entre la obra y el investigador. Cabe destacar que dicho monólogo se encuentran relacionados con la obra teatral seleccionada la cual fue Fotomatón (1995) siendo interpretada por el investigador con el nombre "Autopsia del Personaje Fernando" obedeciendo así a la tercera premisa propuesta por Blumer (1982) el proceso de interpretación, estableciéndose de esta manera la interacción simbólica entre la obra teatral y el investigador.

Sedebemencionaren estepuntolarealización de una adecuación al Sistema Sígnico de Claves propuesto por Gámez (2000) para este tema de estudio, con el fin de identificar las categorías más destacadas presentes en el monólogo se encuentran: Macabro, Comedia y Grotesco; a su vez, se agregaron otros elementos que amplían y enriquecen el análisis e interpretación del textos de Ott. La primera clave se encuentran Macabro- Comedia- Humor Negro, en segundo lugar se encuentra Macabro- Comedia Ironía, la tercera clave se encuentra Macabro- ComediaTiempo, seguida de la clave cuarta compuesta por Macabro- Grotesco- Personaje, la quinta clave se constituye con Macabro- Muerte Violencia y por último, la clave sexta se compone de Macabro- Muerte - Asesinato.

De esta forma el sistema propuesto permite identificar lo macabro con cada clave o imagen radical. Estas Imágenes Radicales se percibieron a lo largo del monólogo, las cuales fueron identificadas y explicadas con el término Microanálisis. Posteriormente se realizó un Análisis Final en el monólogo "Autopsia del Personaje Fernando" denominándose Categorización.

En este sentidose entiendepor categorización un recurso de organización de la información, en este sentido Galeano (2004) lo considera como unidades significativas que permite ordenar, agrupar y clasificar la información, permitiendo así comparar, relacionar y clasificar la información. Con la categorización se pudo exponer y confirmar conclusiones, además permitió al investigador visualizar estructuras en el texto en estudiado, facilitando la codificación y conceptualización de los símbolos y signos presentes en la obra Fotomatón (1995).

En el cuadro 1 que se muestra a continuación, se presenta el Sistema Sígnico de Clave, su interpretación, abreviatura y denominación:

Cuadro 1. Sistema Sígnico de Claves.

\begin{tabular}{ccc}
\hline Clave & Abreviatura & Denominación \\
\hline Clave 1: & MCHN & Macabro-Comedia-Humor Negro \\
Clave 2: & MCI & Macabro-Comedia-Ironía \\
Clave 3: & MGT & Macabro- Grotesco- Tiempo \\
Clave 4: & MGP & Macabro- Grotesco- Personaje \\
\hline Clave 5: & MMV & Macabro- Muerte- Violencia \\
\hline
\end{tabular}


Con esta propuesta de Sistema de Claves se puede detectar e identificar el imaginario de Ott sobre lo macabro, abordado desde el Interaccionismo Simbólico propuesto por Blumer (1982).

Para el análisis de la obra se siguió el proceso descrito a continuación: El en monólogo creado por el investigador se tomó en primera instancia los textos con citas textuales de la obra, luego la interacción del investigador, al concluir este procedimiento, se agregaron las Claves identificadas entre paréntesis. Seguidamente se agregó el microanálisis de la clave. Al concluir el monólogo se presenta un análisis final o categorización de la información.

En consecuencia el Interacionismo Simbólico ocurre en el abordaje de la obra Fotomatón (1995) y a su vez se relacionan con el contexto histórico social del país y el imaginario del investigador, evidenciando de esta forma la triangulación de la información como se muestra en la siguiente figura:

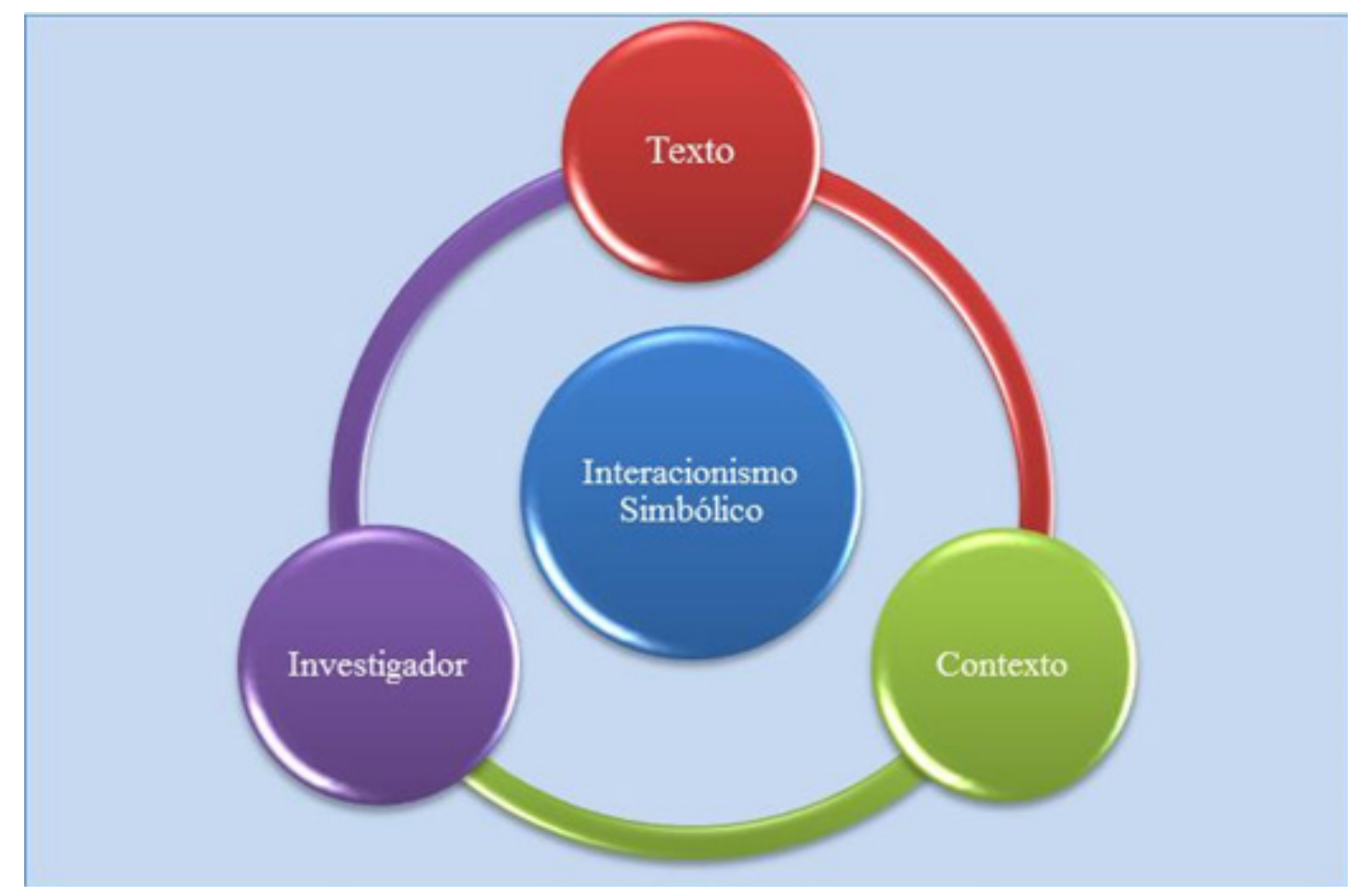

Figura 1. Triangulación de la Información. Fuente: Elaborado por el autor..

Finalmente se presentó el resultado denominado como:

\section{RESULTADOS}

Los resultados obtenidos en esta investigación se basan primeramente en los microanálisis los cuales son la clave del proceso de enseñanza aprendizaje del análisis de un texto dramático, debido al grado de observación y descripción del educando al momento de realizar la creación del monólogo y su interpretación de su contexto partiendo del texto teatral.

Ahora, se presentan la suma de los Microanálisis de las Claves presentes en el texto "Autopsia del Personaje Fernando" producto de la Interacción Simbólica del investigador con la obra Fotomatón (1995) de Gustavo Ott dicha suma se denomina Categorización.

Con respecto a la categorización se presenta el Cuadro 2 donde se indican las Claves que 
obtuvieron mayor o menor frecuencia en el monólogo "Autopsia del Personaje Fernando" producto de la interacción simbólica entre la obra de Ott y el investigador. La clave de mayor Frecuencia ocupará la Posición $\mathrm{N}^{\circ} 1$ y la Clave de menor Frecuencia la Posición $\mathrm{N}^{\circ}$ 6. Las
Frecuencias de las Claves se denominarán $\mathrm{N}^{\circ}$ F., es decir Número de Frecuencia, seguido de la Clave y Número correspondiente, se acota los datos Abreviatura y Denominación.

Cuadro 2. Análisis Final de la obra Fotomatón (1995).

\begin{tabular}{ccccc}
\hline Posición & $\mathbf{N}^{\circ} \mathbf{F}$. & Clave & Abreviatura & Denominación \\
\hline $\mathbf{1}$ & 6 & Clave 4: & MGP & Macabro- Grotesco- Personaje \\
\hline $\mathbf{3}$ & 3 & Clave 1: & MCHN & Macabro-Comedia-Humor Negro \\
$\mathbf{4}$ & 1 & Clave 2: & MCI & Macabro-Comedia-Ironía \\
$\mathbf{5}$ & 1 & Clave 3: & MGT & Macabro- Grotesco- Tiempo \\
\hline $\mathbf{6}$ & 1 & Clave 5: & MMV & Macabro- Muerte- Violencia \\
\hline
\end{tabular}

CONCLUSIONES

En concordancia con la identificación de las claves la obra Fotomatón (1995) se llegó a la siguiente conclusión: Lo macabro se define como comedia considerado la ironía y el tiempo. Así mismo se deduce lo macabro por su atmósfera lúgubre y su regodeo en símbolos y detalles en relación a la muerte como lo refiere Protto (2012) Ott se regodea en dicho elemento sus detalles y símbolos. En primer término el dramaturgo ubica la obra en una morgue, especialmente en el cuarto de autopsias desarrollando el monólogo alrededor de un cadáver cubierto. De igual modo el texto dramático se relaciona con el enunciado de Huizinga (1982) donde la fantasía y el patetismo de la trama pudieran conmover el ánimo del lector- espectador en medio de una atmósfera lúgubre y angustiosa, por ejemplo en la didascalia de la obra Fotomatón (1995) se puede leer "En medio de la escena, una camilla con un cuerpo cubierto" (p. 3) Esta constante alusión a lo macabro se encuentra a lo largo del texto de Ott la imaginería de la muerte, lo mítico y lo fantástico hace presencia en el mundo de real, obedeciendo esta afirmación a la definición de Freud (1919) al indicar que lo macabro se encuentra estrechamente relacionado a lo terrorífico, lo que debería estar oculto, se hace presente.

Por otra parte se puede inferir que la obra Fotomatón (1995) es una comedia macabra con rasgos de humor negro e ironía, dado que 
el género teatral al que pertenece es comedia por su estructura y desarrollo del texto. El tema de la muerte es tratado de manera hilarante o burlesca provocando en el lector- espectador la risa, en este sentido Sánchez (1997) comenta que lo cómico como categoría estética trata temas serios y su resolución se efectúa en una nimiedad. Además esgrime que lo irónico es una crítica constante de manera fingida, el texto estudiado está lleno de ironías, por ejemplo en la obra de teatro Fernando dice: "Odiar es querer" (p. 3) esto al referirse a sus relaciones Familiares la cual es disfuncional. El dramaturgo toma el humor negro como elemento importante para ser crítico de la sociedad venezolana y así incentivar al lector- espectador a tomar conciencia de su realidad.

Asimismo lo macabro se define como grotesco en el personaje Fernando y esto obedece a la definición de De Toro (1990) el cual indica que existe "un contraste chocante entre la forma y el contenido" (p. 155) Si bien el personaje principal está muerto, su fantasma hace acto de presencia en la escena y narra los hechos de su deceso, igualmente la "mezcla inestable de elementos heterogéneos" (De Toro, 1990, p.155) la vida y la muerte, lo macabro y lo grotesco se unen en un mismo personaje en el momento en que el fantasma (personaje) interpreta a su prima, al tío, a su hermano, la madre, el padre y al Dr. Forense todos ellos con cualidades distintas, sin embargo giran alrededor del deceso del personaje principal pudiendo desencadenar en el lector- espectador una mescla explosiva de horror y risa.

Las categorías de lo macabro definido como grotesco se presentan en el texto de Ott por cuanto el personaje que asesina a Fernando es un travesti, respondiendo a la afirmación de De Toro (1990) lo cual es una paradoja la cual resulta aterradora y a la vez ridícula. Después de ser amantes de una noche el travesti le quita la vida en medio del estadio de béisbol.

Con respecto al contexto histórico social en que fue escrita la obra Fotomatón (1995) se encuentra en el período presidencial de Rafael Caldera (1994- 1999) dicho mandato se encontraba envuelto en una crisis económica y social, desde el punto de vista político los partidos tradicionales habían perdido popularidad debido al despilfarro y mal manejo de las arcas nacionales en sus diversos períodos de gobiernos, Rodríguez (2010) señala que en dicho período se deterioraron mucho más los servicios públicos, decreció el nivel de vida de la población, no se restableció el equilibrio económico debido a la crisis financiera durante el gobierno de Caldera. En relación a lo antes expuesto, la inconformidad de la población venezolana se evidencia en el texto de Ott en torno al personaje Fernando Padre al expresar que abandonaban el país todos aquellos que lo desfalcaron económica, política y moralmente.

En el proceso de análisis, se debe señalar el beneficio aportado por esta investigación la novedosa manera de interpretación de una obra de teatro desde una óptica del texto, contexto e investigador, esto se debe a la triangulación aplicada, también al aporte de un nuevo texto dramático, es decir el monólogo, en el cual el investigador pasa de ser lector-espectador a creador de un nuevo texto, donde interpreta los símbolos y signos y su vez los plasma en su creación.

La importancia del monólogo como estrategia de análisis en el proceso de enseñanza y aprendizaje en el área teatral resalta el reconocimiento de los diversos géneros, estilos, tema abordado por el dramaturgo y la estructura dramática. Además coloca al investigador como 
protagonista del texto y contexto de la obra al interpretarla en primera persona, debido a la conjugación del texto y la intertextualidad desarrollada por el educando producto del proceso hermenéutico y su propio contexto.

\section{REFERENCIAS}

Arias, F. (2008) Perfil del profesor de metodología de la investigación en educación superior. Trabajo de Grado. Universidad Central de Venezuela. Caracas [Documento en línea] Disponible en: http://fidiasarias.com/ images/perfil_del_profsor.pdf [Consulta 2016, Julio, 17]

Arias, F. (2012) El Proyecto de Investigación: introducción a la investigación científica. Episteme. Caracas

Blumer, H. (1982) El Interaccionismo Simbólico: perspectiva y método. Barcelona, Hora

De Toro, F. (1990) Semiótica y teatro latinoamericano. [Libro en línea] Disponible:http://http://books.google.co.ve/

Freud, S. (1919) Lo Siniestro. [Libro en línea] Disponible en: https://www.ucm.es/ data/cont/docs/119-2014-02-23-Freud. LoSiniestro.pdf [Consulta 2017, Febrero 15]

Gámez, J. L. (2000) La Cárcel como Espacialidad Dramática En el discurso político del teatro latinoamericano contemporáneo. Cuadernos de Postgrado, Facultad de Humanidades y Educación. UCV. No. 23. Caracas, Venezuela

Galeano, M. (2004) Diseño de proyectos en la Investigación Cualitativa. [Libro en línea] Disponible en: https://books.google.co.ve/ books? id=Xkb78OSRMI8C \&pg=PA38\&dq $=$ la + categorizaci $\%$ C3\%B3n+en+la+investig aci\%C3\%B3n+cualitativa\&hl=es-419\&sa $=\mathrm{X}$ \&ved=0ahUKEwi89Lz4joDVAhVhJ5oKHT DhDZgQ6AEIKjAB\#v=onepage $\& \mathrm{q}=\mathrm{la} \% 20$ categorizaci $\%$ C3\%B3n \% 20 en $\% 201$ a $\% 20$ investigaci $\% \mathrm{C} 3 \% \mathrm{~B} 3 \mathrm{n} \% 20$ cualitativa $\& \mathrm{f}=$ false [Consulta 2016, julio 10]

García, E. (1988) Investigación y experiencia. Una teoría práctica sobre la evaluación [Revista en línea] Disponible en: http:// www.mecd.gob.es/dctm/revista-deeducacion/articulosre287/re28709.
pdf?documentId $=0901$ e 72 b8 13 c300a

[Consulta 2016, julio 16]

Huizinga, J. El otoño de la Edad Media. Alianza editorial. Madrid

Márquez, E. (2008) DISEÑO EMERGENTE EN LA INVESTIGACIÓN CUALITATIVA. [Página Web en Línea] Disponible en: https://investigacionubv.wordpress. com/2012/03/17/diseno-emergente-en-lainvestigacion-cualitativa/ [Consulta, Enero 20, 2015]

Martínez, M. (2007) Ciencia y Arte en metodología cualitativa. Trillas. México

Ott, G. (2015) Fotomatón, 1996. [Página web en línea] Disponible en: www.gustavoott. com.ar/arc/obrasEs/16_fotomaton.pdf. [Consulta, Enero 11, 2015]

Protto, E. (2012) Antología Macabra. [Libro en Línea] Disponible en: https://books.google. co.ve/books?id=7zmmAwAAQBAJ\&pg $=\mathrm{P}$ $\mathrm{T} 5 \& \mathrm{dq}=$ macabro + atm $\% \mathrm{C} 3 \% \mathrm{~B} 3 \mathrm{sfera}+1 \% \mathrm{C} 3$ $\% \mathrm{BAgubre}+\mathrm{y}+\mathrm{con}+$ relaci\%C3\%B3n+a+la+ muerte $+\mathrm{y}+\mathrm{su}+\mathrm{imaginer} \% \mathrm{C} 3 \% \mathrm{ADa} \& \mathrm{hl}=\mathrm{es}-$ 419\&sa $=X \& v e d=0 a h U K$

Rodríguez Rojas, P. (2010) Venezuela: del neoliberalismo al socialismo del siglo XXI. Revista Electrónica. Política y Cultura. Disponible: Disponible: http:// www.scielo.org. $\mathrm{mx} /$ scielo.php? script $=\mathrm{sci}$ arttext\&pid=S0188-77422010000200009 [Consulta: Enero 15, 2015]

Sánchez, A. (1997) Invitación a la Estética. Grijalbo. México

Sandín, M. P. (2003) Investigación cualitativa en educación: fundamentos y tradiciones. McGraw-Hill. México

Tamayo, M. (2003) El Proceso de la Investigación Científica. Limusa. México

Terán, G. (2006) Paradigmas de investigación: Concepciones básicas. Papel de trabajo $\mathrm{N}^{\circ}$ 1. Soboc Grafic. Universidad equinoccial. Quito Ecuador. [Documento en línea] Disponible en: http://app.ute.edu.ec/ content/3344-23-59-1-23-17/PAPEL\%20 D E \% 20 T R A B A J O \% 20 U N O \% 20 PARA DIGMA S \% 20 DE \% 20 L A \% 20 INVESTIGACI\%C3\%93N.pdf. [Consulta: 2015, Enero 31] 
Zavala, L. (1999) Intertextos e hipertextos. [Documento en línea] Disponible en: revistas.javeriana.edu.co/index.php/cualit/ article/download/6764/5403 [Consulta, noviembre 17, 2015] 